\title{
Median and ulnar nerve conduction determinations in the Erb's point-axilla segment in normal subjects
}

\author{
MEJER G INZBURG, MATHEW LEE, JEHUDIT G I NZBURG, \\ A N D A UG USTA A L B A \\ From the Electrodiagnostic Unit, Department of Rehabilitation Medicine, New York University \\ Medical Centre, Goldwater Memorial Hospital, Roosevelt Island, New York, USA
}

SUMMARY Twenty-one median and 22 ulnar nerves were tested in 12 patients for motor nerve conduction velocity (MNCV) and motor nerve conduction time (MNCT) in the segments from Erb's point (N) to axilla (A) bilaterally. It was found that on this segment for both nerves, MNCV values equal to or smaller than $51 \mathrm{~m} / \mathrm{s}$ or conduction times equal to or longer than $4 \mathrm{~ms}$ are to be considered abnormal. For comparative studies and for checking the normality of the tested nerves in their entire length, the more distally located segments in the same nerve were also tested. For diagnostic purposes, the differences between right and left MNCV or MNCT values determined in the same person on $\mathrm{N}$-A segments of homologous nerves were analysed. Motor nerve conduction velocity or MNCT determinations on the N-A nerve segment are expected to replace MNCV determinations on the longer $\mathrm{N}-\mathrm{AE}$ ( $\mathrm{AE}=100 \mathrm{~mm}$ above elbow) nerve segment, which is now in use, for diagnosis of the thoracic outlet syndrome.

In the vast literature on nerve conduction determination for different nerves and their segments, a number of reports exist on nerve conduction studies in the upper extremities in which the Erb's point was the most proximal point of stimulation (Dejerine and Bernheim, 1899; Bauwens, 1961; Dobbelstein and Struppler, 1963; Gassel and Diamantopoulos, 1964; Jebsen, 1966, 1967; Caldwell et al., 1971; Urschel et al., 1971; Urschel and Razzuk, 1972; Daube, 1975; London, 1975; Cherington, 1976). However, these authors determined the motor nerve conduction velocity (MNCV) on a nerve segment N-AE, that is, between the Erb's point $N$ (neck) and a point AE (above elbow). This was usually $100 \mathrm{~mm}$ above the elbow. There is no published account of nerve conduction determinations in the nerve segment between Erb's point and axilla (A). We have studied nerve conduction in the N-A segment in a number of diseases. The results will be published elsewhere. In the present paper the MNCV and motor nerve conduction times

Address for reprint requests: Mejer Ginzburg, MD, FACP. Department of Rehabilitation Medicine, New York University Medical Center, Goldwater Memorial Hospital, Roosevelt Island, New York 10044, USA.

Accepted 3 January 1978
(MNCT) values obtained in the $\mathrm{N}-\mathrm{A}$ segment of the median and ulnar nerves of only normal subjects will be presented.

\section{Methods}

The population studied consisted of eight females and four males all in good health. The age ranged from 26 to 55 years, with a mean value of 37.1 years.

Every subject was tested clinically and with appropriate laboratory tests to eliminate those with a peripheral neuropathy or a disease which may be accompanied by a latent peripheral neuropathy.

The apparatus used for all nerve conduction studies was a two-channel TECA model TE2-7 electromyograph which included a stimulation unit. Skin pick-up electrodes were $6 \mathrm{~mm}$ in diameter. The active (stigmatic) electrode was placed over the motor point of the abductor pollicis brevis muscle for investigating the median nerve, and of the abductor digiti minimi for the ulnar nerve. The reference electrode was placed at the distal tendon of the corresponding muscle. The earth (ground) electrode was placed on the dorsum of the tested hand. Stimulation was performed with a regular TECA biprong stimulation 
probe. The skin beneath the electrodes was scrubbed with sandpaper and cleaned with alcohol. Electrocardiograph jelly was used for the electrodes. Although our main goal was the determination of MNCV and MNCT in the nerve segments between $\mathrm{N}$ and $\mathrm{A}$, for purposes discussed later each tested nerve was stimulated at four locations: N, A, E (elbow), and W (wrist). Therefore, four motor latencies were obtained for each nerve tested. At all of the above sites of stimulation, the location of the stimulating cathode was carefully adjusted to obtain a perfectly matching configuration of the evoked action potential for each stimulation. Only such tracings were accepted for further calculation (Figure). The location of the stimulating cathode at Erb's point was lateral to the clavicular insertion of the lateral head of the sternocleidomastoid muscle, just above the clavicle. At the wrist, the stimulating cathode was always placed at a constant distance of $55 \mathrm{~mm}$ from the corresponding muscle pick-up electrode. The constant distance for all wrist motor latencies is accepted routinely in our laboratory to make more reliable comparisons of obtained results.

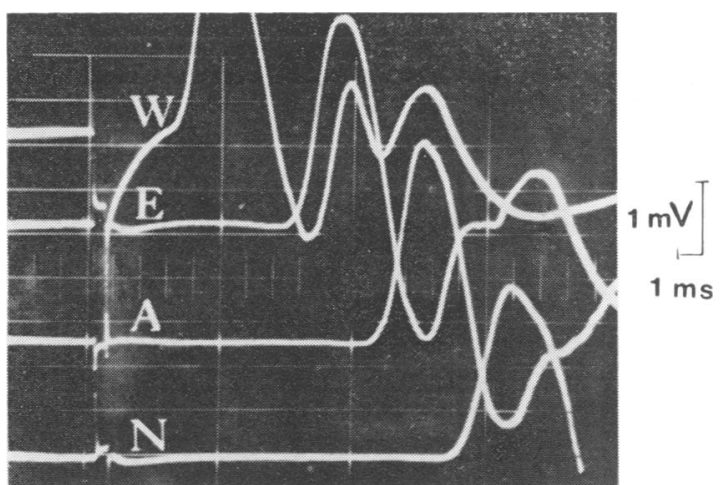

Figure Four typical tracings from the left median nerve obtained in one subject. Sites of stimulation at $W$-wrist, E-elbow, $A$-axilla, and $N$-Erb's point.

Whenever possible the tests were performed bilaterally on the median and ulnar nerves, so that 16 determinations were obtained in each subject. All studies were done on each subject during one session. The procedure for each test was supramaximal stimulation at the wrist, at the elbow (conventional location), axilla, and Erb's point, in that order.

The square pulses of current used for stimulation were $0.1 \mathrm{~ms}$ duration at the wrist and elbow. At the axilla and Erb's point a longer pulse duration of $0.2 \mathrm{~ms}$ or $0.5 \mathrm{~ms}$ was needed. The latter was the more frequently used. Oscilloscope sweep speed was $5 \mathrm{~ms}$ per $25.4 \mathrm{~mm}$ division. Photographs were taken with a Polaroid Land camera (Figure). Motor nerve conduction velocities were calculated in the conventional way for each of the three proximal tested segments N-A, A-E, and E-W. The distances between cathodes were measured with a tape measure, except for the distance between Erb's point and the axilla where a caliper was used (Jebsen, 1967).

The subject was lying supine with his arm in $60^{\circ}$ abduction at the shoulder, elbow extended, and the forearm in supination. This position is believed to place the brachial plexus with the peripheral median and ulnar nerves as close to a straight line as possible and to make the measurement of the N-A nerve segments most reliable. This position also provides an ample approach to the axilla for the proper placement of the stimulator on individual nerves. Optimal placement gave us an evoked action potential which was well matched with those obtained at all other sites of stimulation on the same nerve. The widely exposed axilla also made it easier to place properly the distal leg of the caliper when measuring the $\mathrm{N}-\mathrm{A}$ nerve segment. The room temperature was between $25-26.7^{\circ} \mathrm{C}$. The subject was resting for at least 30 minutes on a plinth before the start of the session and was covered with a blanket to the midchest.

\section{Results}

The mean values with their standard deviations (SD), and the ranges of the obtained MNCV for all tested nerve segments are presented in Table 1.

Table 1 Motor nerve conduction velocities (MNCV) in $N-A$ and more distal segments of median and ulnar nerves bilaterally

\begin{tabular}{llllll}
\hline Nerve & $\begin{array}{l}\text { Number of } \\
\text { segments }\end{array}$ & Segment & $\begin{array}{l}\text { Mean } \\
(\mathrm{m} / \mathrm{s})\end{array}$ & $\begin{array}{l}S D \\
(\mathrm{~m} / \mathrm{s})\end{array}$ & $\begin{array}{l}\text { Range } \\
(\mathrm{m} / \mathrm{s})\end{array}$ \\
\hline Median & 21 & N-A & 65.1 & \pm 6.1 & $57.1-76.2$ \\
Median & 21 & A-E & 56.3 & \pm 5.1 & $50.0-68.3$ \\
Median & 21 & E-W & 49.0 & \pm 3.9 & $45.1-54.4$ \\
Ulnar & 22 & N-A & 63.0 & \pm 5.5 & $55.0-73.2$ \\
Ulnar & 22 & A-E & 51.2 & \pm 4.2 & $44.9-60.6$ \\
Ulnar & 22 & E-W & 48.9 & \pm 2.8 & $45.2-55.3$ \\
\hline
\end{tabular}

$\mathrm{N}=$ neck (Erb's point); $\mathrm{A}=$ axilla $; \mathrm{E}=$ elbow; $\mathrm{W}=$ wrist

Table 2 Motor terminal latencies of the median and ulnar nerves bilaterally

\begin{tabular}{lllll}
\hline & $\begin{array}{l}\text { Number of } \\
\text { terminal } \\
\text { latencies }\end{array}$ & $\begin{array}{l}\text { Mean } \\
(\mathrm{ms})\end{array}$ & $\begin{array}{l}\text { SD } \\
(\mathrm{ms})\end{array}$ & $\begin{array}{l}\text { Range } \\
(\mathrm{ms})\end{array}$ \\
\hline Merve & 21 & 3.9 & \pm 0.37 & $3.4-4.5$ \\
Ulnar & 22 & 3.5 & 0.36 & $2.8-4.2$ \\
\hline
\end{tabular}


The mean and SD values, and the ranges of the observed motor terminal latencies of the same nerves, are presented in Table 2 . In these Tables the values obtained from right and left segments of a homologous nerve were treated in one pool.

Table 3 presents the mean, SD, and ranges of the MNCT values for the N-A segments of the median and ulnar nerves. Here again, the values obtained from the right and left segments of a homologous nerve were treated in one pool.

Table 3 Motor nerve conduction time in the N-.4 segment of the median and ulnar nerves bilaterally

\begin{tabular}{lllll}
\hline Nerve & $\begin{array}{l}\text { Number of } \\
\text { segments }\end{array}$ & $\begin{array}{l}\text { Mean } \\
(\mathrm{ms})\end{array}$ & $\begin{array}{l}S D \\
(\mathrm{~ms})\end{array}$ & $\begin{array}{l}\text { Range } \\
(\mathrm{ms})\end{array}$ \\
\hline Median & 21 & 2.9 & \pm 0.4 & $2.1-3.4$ \\
Ulnar & 22 & 3.1 & \pm 0.4 & $2.6-3.9$ \\
\hline
\end{tabular}

Table 4 shows how the mean, SD, ranges and (mean $-2 \mathrm{SD}$ ) values we obtained for the MNCV on N-A segments for the median and ulnar nerves behave in comparison with comparable values obtained by other authors as calculated by them on the larger N-AE nerve segments.

Table 5 presents the mean and SD of the differences between the normal MNCV values obtained in the same subjects for right and left N-A segments and the more distally located nerve segments for homologous nerves.

Table 6 presents the differences we have found between right and left MNCV values on the N-A nerve segments in comparison with similar right and left difference values obtained by London (1975) on the larger N-AE segments.

\section{Discussion}

In our determination of $\mathrm{MNCV}$ values in the bilateral N-A segments of the median and ulnar
Table 5 Means and standard deviations for the differences in $M N C V$ values found in symmetrical nerve segments of right and left homologous nerves in the upper extremities

\begin{tabular}{llll}
\hline \multicolumn{5}{c}{ Median nerve } \\
\cline { 2 - 4 } Nerve segment & $\begin{array}{l}\text { Number of } \\
\text { subjects }\end{array}$ & $\begin{array}{l}\text { Mean right-left } \\
\text { difference }(\mathrm{m} / \mathrm{s})\end{array}$ & $\begin{array}{l}S \mathrm{~S} \\
(\mathrm{~m} / \mathrm{s})\end{array}$ \\
\hline $\mathrm{N}-\mathrm{A}$ & 9 & 7.5 & \pm 4.9 \\
$\mathrm{~A}-\mathrm{E}$ & 9 & 4.8 & $: 4.4$ \\
$\mathrm{E}-\mathrm{W}$ & 9 & 2.0 & \pm 1.6 \\
& Ulnar nerve & & \\
N-A & 10 & 4.0 & \pm 4.3 \\
A-E & 10 & 4.9 & \pm 2.7 \\
E-W & 10 & 1.7 & \pm 2.1 \\
\hline
\end{tabular}

$\mathrm{N}=$ Erb's point $; \mathrm{A}=\mathrm{axilla} ; \mathrm{E}=$ elbow; $\mathrm{W}=$ wrist

Table 6 Comparison of ranges of differences between our right and left mean MNCV values for the $N-A$ segment with studies by London (1975) on the N-AE nerve segment

\begin{tabular}{lll}
\hline & \multicolumn{2}{l}{ Ginzburg et al (1978) } \\
\cline { 2 - 3 } Nerve & $\begin{array}{l}\text { Experimental } \\
(\mathrm{m} / \mathrm{s})\end{array}$ & $\begin{array}{l}\text { Calculated from } \\
\text { mean } \pm 2 S D \\
(\mathrm{~m} / \mathrm{s})\end{array}$ \\
\hline Median & $1.5-14.1$ & $0.0-17.3$ \\
Ulnar & $0.2-12.3$ & $0.0-12.6$ \\
Ulnar & London $(1975)$ & \\
\hline
\end{tabular}

$\mathrm{N}=$ Erb's point $; \mathrm{A}=$ axilla $\mathrm{AE}=100 \mathrm{~mm}$ above elbow

nerves in normal subjects, we measured simultaneously the MNCV values for the more distal nerve segments of these nerves, in order to compare values of the MNCV in the N-A segment (not previously determined) with the MNCV values in the more distal segments. These additional measurements also enabled us to determine that a tested nerve was intact in its entire length. Despite thorough screening techniques to

Table 4 Comparison of the MNCV values obtained in the $N$ - $A$ segment with corresponding data obtained by other authors in the $N-A E$ nerve segments

\begin{tabular}{|c|c|c|c|c|c|}
\hline \multirow[b]{2}{*}{ Authors } & \multirow[b]{2}{*}{ Nerve segment } & \multicolumn{4}{|l|}{ Median nerve } \\
\hline & & Mean $M N C V(m / s)$ & $S D(\mathrm{~m} / \mathrm{s})$ & Range $(\mathrm{m} / \mathrm{s})$ & Mean-2SD $(\mathrm{m} / \mathrm{s})$ \\
\hline \multirow[t]{2}{*}{$\begin{array}{l}\text { Ginzburg et al (1978) } \\
\text { Jebsen (1967) } \\
\text { Daube (1975) } \\
\text { Cherington (1976) } \\
\text { London (1975) }\end{array}$} & $\begin{array}{l}\mathrm{N}-\mathrm{A} \\
\mathrm{N}-\mathrm{AE} \\
\mathrm{N}-\mathrm{AE} \\
\mathrm{N}-\mathrm{AE} \\
\mathrm{N}-\mathrm{AE}\end{array}$ & $\begin{array}{l}65.1 \\
62.9\end{array}$ & $\begin{array}{l}+6.1 \\
+6.0\end{array}$ & $\begin{array}{l}57.1-76.2 \\
51.0-76.0\end{array}$ & $\begin{array}{l}52.9 \\
50.9\end{array}$ \\
\hline & & \multicolumn{4}{|l|}{ Ulnar nerve } \\
\hline $\begin{array}{l}\text { Ginzburg et al (1978) } \\
\text { Jebsen (1967) } \\
\text { Daube (1975) } \\
\text { Cherington (1976) } \\
\text { London (1975) }\end{array}$ & $\begin{array}{l}\mathrm{N}-\mathrm{A} \\
\mathrm{N}-\mathrm{AE} \\
\mathrm{N}-\mathrm{AE} \\
\mathrm{N}-\mathrm{AE} \\
\mathrm{N}-\mathrm{AE}\end{array}$ & $\begin{array}{l}63.0 \\
61.3 \\
60.8 \\
59.0 \\
58.9\end{array}$ & $\begin{array}{l} \pm 5.5 \\
\square 5.4\end{array}$ & $\begin{array}{l}55.0-73.2 \\
52.0-78.0\end{array}$ & $\begin{array}{l}52.0 \\
50.5\end{array}$ \\
\hline
\end{tabular}

$\mathrm{N}=$ Erb's point; $\mathrm{A}=$ axilla; $\mathrm{AE}=100 \mathrm{~mm}$ above elbow; $\mathrm{E}=\mathrm{elbow}$ 
eliminate subjects with a possible peripheral neuropathy, some MNCV or terminal latency values of these apparently normal subjects were found to be "abnormal," and all data obtained in these nerves were eliminated from our study.

One of our goals was to determine for the N-A segment of the median and ulnar nerves the lowest MNCV value below which a value would have to be considered pathological. Theoretical statistics provide for this purpose the formula "mean $\pm 2 S D$ " where mean and SD are known values. The theoretical low borderline value for MNCV of the N-A segment of the median nerve is 52.9 $\mathrm{m} / \mathrm{s}$ and of the ulnar nerve $52.0 \mathrm{~m} / \mathrm{s}$ (Table 1). Our experimental low borderline value for the median nerve is $57.1 \mathrm{~m} / \mathrm{s}$, and for the ulnar nerve it is $55.0 \mathrm{~m} / \mathrm{s}$ (Table 1). Therefore, for practical purposes we can accept any MNCV of the N-A nerve segment found to be equal to or smaller than $51 \mathrm{~m} / \mathrm{s}$ as pathological.

Using data from Table 3 and the formula given above, the theoretical upper limit for MNCT of the $\mathrm{N}$-A segment of the median nerve is $3.7 \mathrm{~ms}$, and of the ulnar nerve is $3.9 \mathrm{~ms}$. Our experimental upper limit for the median nerve is $3.4 \mathrm{~ms}$, and for the ulnar nerve it is $3.9 \mathrm{~ms}$. Therefore, for practical purposes we can accept any MNCT of the N-A nerve segment found to be equal to or larger than $4.0 \mathrm{~ms}$ as abnormal.

The MNCV values obtained on the $\mathrm{N}$-A nerve segments were compared with those obtained in the more distal nerve segments. Table 1 shows that the figures obtained for the mean, SD, and MNCV ranges conform with the general rule of distal MNCV slowing discussed in detail by Trojaborg (1964).

The application of this rule will be helpful in the analysis of Table 4 . Comparing the values in the different columns we obtained in the $\mathrm{N}-\mathrm{A}$ nerve segment with the corresponding values obtained by other authors in the N-AE segment, it will be noted that our values are somewhat larger. This finding can easily be explained by the fact that each $\mathrm{N}$-AE nerve segment contains the entire $\mathrm{N}-\mathrm{A}$ segment as well as an A-AE segment in which MNCV is slower than in the N-A segment according to the above rule.

An additional aspect of our data which was analysed was the difference between right and left MNCV values and MNCT values on corresponding nerve segments. When the MNCV value determined in a peripheral nerve segment falls into the lower range of normal, or is a borderline value, it is advisable to compare this result with the MNCV value determined on the contralateral side. If the difference between the two normal MNCV values is larger than an accepted normal minimum, this may have diagnostic significance. The smaller MNCV value should suggest the possibility of a developing abnormality. Periodic follow-up nerve conduction tests in the nerve segment with the lower MNCV could show a trend of increasing or decreasing MNCV values and in this way deny or confirm developing pathology (Trojaborg, 1964; London, 1975). For this purpose, Table 5 was compiled. It includes the means and SD of the MNCV differences for the right and left N-A and more distally located nerve segments, separately for the median and ulnar nerves. The values show a tendency to increase with the more proximal location of the nerve segment. This phenomenon was noted and the possible origin of this trend was discussed by London (1975).

A comparison of our results of the ranges of the differences of the right-left MNCV values on $\mathrm{N}-\mathrm{A}$ segments with those presented by London (1975) for the N-AE nerve segments is of interest and is presented in Table 6 . The ranges in the column entitled "Experimental" were derived from the raw data obtained for each subject on the tested nerve segments bilaterally. The ranges for both the experimental and theoretical values on the N-A nerve segments are somewhat larger than those obtained on the N-AE nerve segments. Again this is explained by the trend that the more proximally the symmetrical nerve segments of a homologous nerve are located, the greater is the mean difference between the right and left MNCV values determined on these segments. London (1975) accepts that a right-left MNCV difference on the N-AE segment of $9 \mathrm{~m} / \mathrm{s}$ or larger should raise suspicion of possible pathology in the $\mathrm{N}-\mathrm{AE}$ nerve segment with the smaller MNCV value. $\mathrm{He}$ advised regular periodic follow-up of MNCV determinations on the nerve segment with the lower MNCV as discussed above. On the basis of our data in Table 6, we accept for the median $\mathrm{N}$-A nerve segments the upper limit of normal differences between right and left $\mathrm{MNCV}$ values to be $14 \mathrm{~m} / \mathrm{s}$. Any greater difference must raise suspicion of possible developing local pathology and follow-up studies must be done; for the ulnar nerve we accept a maximal normal MNCV difference of $12 \mathrm{~m} / \mathrm{s}$. Testing of a larger group of patients may modify these values in the future.

MNCV studies of the ulnar nerve on N-AE nerve segments in preoperative patients with a thoracic outlet syndrome have evoked great interest. (Caldwell et al., 1971; Urschel et al., 1971; Urschel and Razzuk, 1972; Daube, 1975; London, 1975; Cherington, 1976). However, the $\mathrm{N}-\mathrm{AE}$ segment is composed of a $\mathrm{N}-\mathrm{A}$ segment in 
which a lesion is expected in a great number of cases of thoracic outlet syndrome and the A-AE segment which is not expected to have any damage in this syndrome. Therefore, the MNCV value obtained on the N-AE nerve segment, being the mean of an expected normal value on the A-AE segment and an expected abnormal MNCV value on the $\mathrm{N}$-A segment may be larger than that obtained on the shorter N-A segment alone. The MNCV value may even fall into a normal range, when if calculated on the shorter N-A segment alone, it would show pathology. It is our impression that MNCV studies on the smaller $\mathrm{N}-\mathrm{A}$ nerve segment in patients suspected of developing a thoracic outlet syndrome will give more precise preoperative diagnostic data and consequently better postoperative results. In the early stages of a possible thoracic outlet syndrome with normal bilateral MNCV values on the $\mathrm{N}$-A nerve segments but with a right-left value difference greater than those previously suggested, serial MNCV determinations of the bilateral N-A segments may show a pathological trend and confirm the need for corrective surgery in this subject.

Our findings that MNCT values of $4 \mathrm{~ms}$ or longer are abnormal, can also be used in the diagnosis of thoracic outlet syndrome. Determination of MNCT in a N-A segment is a simpler procedure since no caliper measurements are needed. Two well-matched tracings obtained after stimulation at Erb's point and the axilla are sufficient for the MNCT determinations. In cases where the MNCT values are close to the borderline value of $4.0 \mathrm{~ms}$, serial MNCT determinations are required, and a trend of increasing values will indicate local N-A nerve segment pathology and will contribute to the differential diagnosis of thoracic outlet syndrome or other insidiously developing peripheral neuropathies.

We would like to acknowledge the assistance of the following staff members in the preparation of this paper: Dr Eugenio Alejano Jr., in the practical performance of the tests; Dr Herbert Zaretsky and Dr Bernard Brucker for statistical consultation; again Dr Herbert Zaretsky, Dr Masayoshi Itoh, and Ms Arleen Mandia for editorial advice.

\section{References}

Bauwens, P. (1961). Electrodiagnosis revisited. Tenth John Stanley Coulter Memorial Lecture. Archives of Physical Medicine and Rehabilitation, 42, 6-18.

Caldwell, J. W., Crane, C. R., and Kruzen, E. M. (1971). Nerve conduction studies: an aid in the diagnosis of the thoracic outlet syndrome. Southern Medical Journal, 64, 210-212.

Cherington, M. (1976). Ulnar conduction velocity in thoracic-outlet syndrome. New England Journal of Medicine, 294, 1185.

Daube, J. R. (1975). Nerve conduction studies in thoracic-outlet syndrome. Neurology (Minneapolis), $25,347$.

Dejerine, J. J., and Bernheim, H. M. (1899). Sur un cas de paralysie radiale par compression, suivi d'autopsie. Revue Neurologique, 7, 785-788.

Dobbelstein, H., and Struppler, A. (1963). Die nervenleitgeschwindigkeit als diagnostisches kriterium bei peripheren neurologischen störungen. Fortschritte der Neurologie Psychiatrie und Ihrer Grenzgebiete, 31, 616-636.

Gassel, M. M., and Diamantopoulos, E. (1964). Pattern of conduction times in the distribution of the radial nerve. A clinical and electrophysiological study. Neurology (Minneapolis), 14, 222-231.

Jebsen, R. H. (1966). Motor conduction velocity in proximal and distal segments of the radial nerve. Archives of Physical Medicine and Rehabilitation, 47, 597-602.

Jebsen, R. H. (1967). Motor conduction velocities in the median and ulnar nerves. Archives of Physical Medicine and Rehabilitation, 48, 185-194.

London, G. W. (1975). Normal ulnar nerve conduction velocity across the thoracic outlet: comparison of two measuring techniques. Journal of Neurology, Neurosurgery, and Psychiatry, 38, 756-760.

Trojaborg, W. (1964). Motor nerve conduction velocities in normal subjects with particular reference to the conduction in proximal and distal segments of median and ulnar nerve. Electroencephalography and Clinical Neurophysiology, 17, 314-321.

Urschel, H. C., and Razzuk, M. A. (1972). Management of the thoracic-outlet syndrome. New England Journal of Medicine, 286, 1140-1143.

Urschel, H. C., Razzuk, M. A., Wood, R. E., Parekh, M., and Paulson, D. L. (1971). Objective diagnosis (ulnar nerve conduction velocity) and current therapy of the thoracic outlet syndrome. Annals of Thoracic Surgery, 12, 608-620. 